\title{
Skin - A Mirror Reflecting Underlying Obesity
}

\author{
Dr.K.Hanuma Naik Md,Vd(Std) ${ }^{1,}$ Dr.S.Nageswarammamd,VD (STD) ${ }^{2}$ \\ ${ }^{1}$ Asst Prof In Dvl Dept, Gmc, Guntur. \\ ${ }^{2}$ Prof\&Hod, In Dvl Dept(Guntur Medical College, Ntruhs, Andhra Pradesh,India)
}

\begin{abstract}
:
Introduction: Obesity is a global problem, epidemic in some areas and on the rise in others. One of the most important, yet preventable health hazards worldwide. Obesity causes a multitude of skin changes, which gives us clue of underlying obesity. These include acanthosisnigricans, acrochordons, striae distensae, keratosis pilaris, adiposis dolorosa, increased infections .

Aim: To study the incidence of various dermatological manifestations seen in obese subjects and to correlate between the severity of obesity and skin changes.

Materials and methods: The present study was conducted for a period of one year in department of DVL, GGH, Guntur. Subjects with BMI of $>30$ were included, detailed history was taken and relevant investigations were done to rule out underlying cause for obesity.Observation and results: out of 20,200 patients 77 patients were obese with BMI of $>30$. Most common dermatological finding observed is acanthosis nigricans, with skin tags being the second most common finding with dermatophyte infections third most common.

Conclusion: obesity is a chronic health problem, with numerous complications that affect the skin. Dermatological manifestations of obesity range from annoying to incapacitating. Early recognition and prompt attention to these dermatoses is the corner stone of appropriate management.

Keywords: obesity, acanthosis nigricans, BMI, skin tags, dermatophyte infections
\end{abstract}

\section{Introduction}

Obesity is the accumulation of excess of adipose tissue to an extent that impairs both physical and psychosocial health and well being. It is often neglected, indeed frequently it is not even thought of as a disease, but obesity is one of the most important, yet preventable health hazard. There is alarming increase in obesity in both developed and developing countries.

Obesity increases morbidity and mortality through its multiple effects on nearly every system of the body. It causes multitude of skin changes. Prevalence of obesity changes with age, sex, socioeconomic status.

Age: Prevalence is increasing in children

Sex: more common among women.because women have more fat mass and less lean mass than men and relate to mens ability to deposit more lean than fat tissue when energy imbalance occurs with weight gain ${ }^{[1]}$

Socioeconomic status: more among poor socio economic status. Recent trends show a shift in prevalence from higher to lower socio economic level. ${ }^{[2]}$

Etiopathogenesis: obesity has a multifactorial etiology, It is a result of genetic, environmental, behavioral. Physiological, social and cultural factors. ${ }^{[3]}$

Secondary causes of obesity are hypothyroidism, cushings syndrome, insuinoma, pcod, growth hormone deficiency, type 2 DM, pseudohypoparathyroidism, eating disorders, medications like OCP's and genetic syndromes.

Obesity and the skin: Obesity is associated with a number of dermatoses. It affects cutaneous sensation, temperature regulation, foot shape and vasculature.Acanthosis nigricans is the most common dermatological manifestation of obesity.It increases the incidence of cutaneous infections , leg ulcerations,stasis pigmentation,lymphedema, plantar hyperkeratosis,striae etc.

\section{Aims and Objectives}

1.To study the incidence of various dermatological manifestations occurring in obese subjects.

2.To study the correlation between the severity of obesity and skin changes.

3.To compare the skin changes in male and female subjects with obesity. 


\section{Materials And Methods}

The study period extended for one year. Patients attending to the DVL OPD, GGH, Guntur were enrolled in the study.The patients BMI was calculated by using the formula -weight in kilograms/height in square meters. Subjects who had a BMI of more than 30 were entered in to the study group.

Detailed history was taken and relevant investigations were done to rule out any underlying cause for obesity. Investigations done for all patients include complete urine examination, CBP,RBS,RFT,LFT, Thyroid function tests, USG abdomen.

The patients were divided into two groups based on their sex i.e male and female. Each group was again divided into three groups based on their BMI.

1. obese class 1: 30 to 34.99

2. obese class 2: 35 to 39.99

3. obese class 3: 40 and above

Each patient was examined clinically and skin changes were analysed to find most common changes, common site of involvement, any differences in the pattern between men and women, correlation between degree of obesity and severity of changes

\section{Observation And Results}

Out of 20200 patients attended DVL op, 77 were obese with BMI of >30. Out of these 32patients had underlying systemic or endocrine cause.Remaining 45 patients with no detectable underlying cause were included in the study.On analyzing these 45 cases following results were obtained.

Table 1: Dermatological Findings In The Study Group

\begin{tabular}{|l|l|l|l|}
\hline skin findings & males & females & total \\
\hline Acanthosis nigricans & 5 & 24 & 29 \\
\hline skin tags & 4 & 17 & 21 \\
\hline striae distensae & 3 & 8 & 11 \\
\hline Taenia infection & 6 & 12 & 18 \\
\hline Erythrasma & 2 & 6 & 8 \\
\hline Intertrigo & 2 & 4 & 6 \\
\hline Folliculitis & 2 & 4 & 6 \\
\hline varicose veins & 1 & 4 & 5 \\
\hline keloids & 0 & 2 & 2 \\
\hline Facial hypermelanosis & 0 & 2 & 2 \\
\hline Melasma & 0 & 2 & 2 \\
\hline Herpes genitalis & 1 & 1 & 2 \\
\hline PMLE & 0 & 1 & 1 \\
\hline Scabies & 0 & 1 & 1 \\
\hline MC & 1 & 0 & 1 \\
\hline Miliaria & 0 & 1 & 1 \\
\hline LP & 1 & 0 & 1 \\
\hline seborrheic keratosis & 0 & 1 & 1 \\
\hline ACD & 0 & 1 & 1 \\
\hline seborrheic dermatosis & 0 & 1 & 1 \\
\hline pemphigus foliaceous & 1 & 0 & 1 \\
\hline Teania versicolor & 0 & 1 & 1 \\
\hline Amyloidosis & 0 & 1 & \\
\hline & & & 1 \\
\hline
\end{tabular}

Sex ratio:Out of 45 cases 34 were females and 11 were males

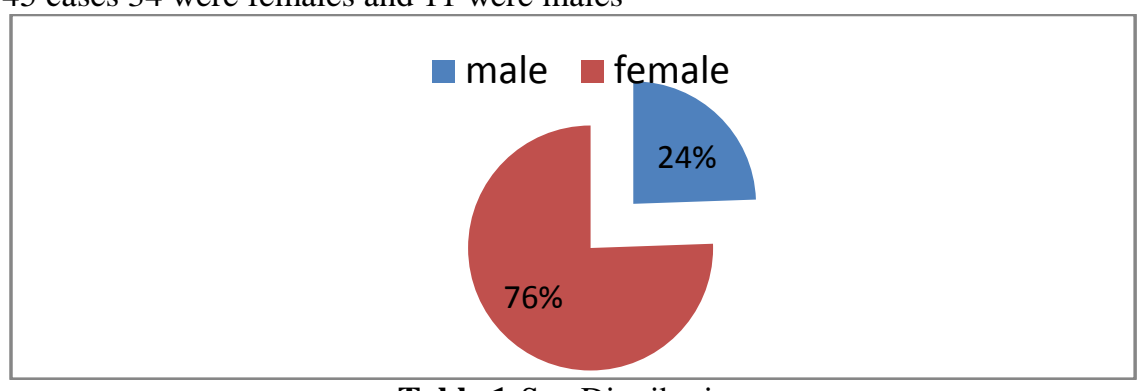

Table 1:Sex Distribution 


\section{Age distribution}

Table 1: Age Distribution

\begin{tabular}{|l|l|l|l|l|l|l|}
\hline & $<20 \mathrm{yrs}$ & $21-30 \mathrm{yr}$ & $31-40 \mathrm{yr}$ & $41-50 \mathrm{yr}$ & $51-60 \mathrm{yr}$ & $>61 \mathrm{yrs}$ \\
\hline male & 1 & 0 & 4 & 1 & 4 & 1 \\
\hline female & 6 & 8 & 11 & 9 & 0 & 0 \\
\hline total & 7 & 8 & 15 & 10 & 4 & 1 \\
\hline
\end{tabular}

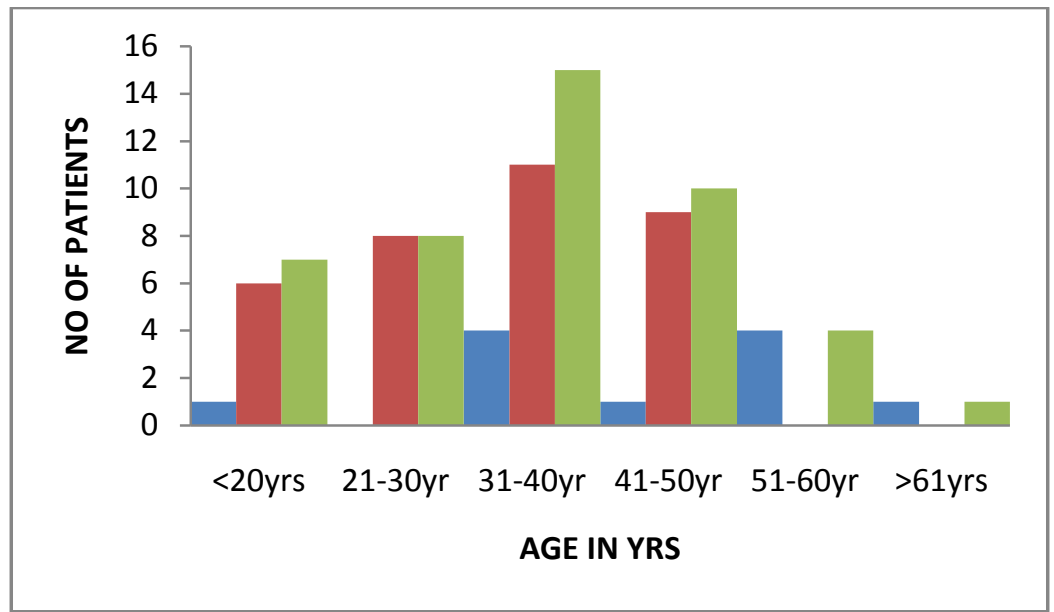

Figure 2 : Bar Diagram Showing Age Distribution

Table 3: Severity Of Obesity

\begin{tabular}{|l|l|l|l|}
\hline obesity grade & male & female & total \\
\hline gr 1 & 8 & 21 & 29 \\
\hline gr 2 & 3 & 11 & 14 \\
\hline gr 3 & 0 & 2 & 2 \\
\hline
\end{tabular}

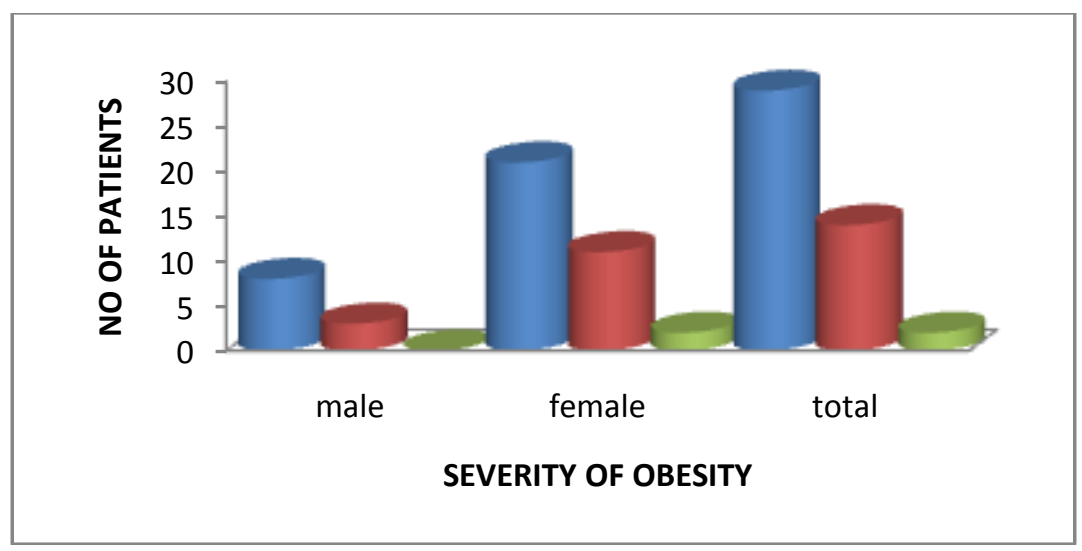

Figure 3 : Showing Severity Grading

\section{DISCUSSION}

Incidence of obesity in the present study is 0.4 per 100 patients. It doesn't reflect the overall incidence in the population as the study group is very small. Male to female ratio is $1: 3.09$, this correlates with 2004 WHO statistics which state that obesity is 3 to 4 times more common in women compared to men. Commonest age group involved was 31 to 40 yrs. A positive family history was present in $60.66 \%$ of cases. Predominant sedentary life style was seen in $71.11 \%$ and $76.47 \%$ were females. This might be the cause for relatively more prevalence of obesity in women.

The most common dermatological finding observed in the study was acanthosis nigricans seen in $64.44 \%$, similar to studies by Hud et $\mathrm{al}^{\left[{ }^{4]}\right.}$ Garcia-Hidalgo et ${ }^{\mathrm{al}[5]}$. the incidence of acanthosis nigricans increased with increasing BMI similar to Hud et al ,Katz et ${ }^{\text {al[6] }}$ and Burke et al ${ }^{[7]}$ studies. commonest site of involvement was $\operatorname{neck}(93.10 \%)$ 
Skin tags were the second most Common finding seen in $46.66 \%$.no positive relation was observed between BMI and occurrence of skin tags in this study. In most of the cases, skin tags occurred along with acanthosis nigricans.

Dermatophyte infections were the third most common finding with most common site being abdominal folds in females and trunk in males. Striae distensae was the next most common finding in this study which showed increase in prevalence with increasing body weight. The most common site was abdomen in females and shoulders in males.Erythrasma was the next commonest finding with common site being axilla in both sexes.

Intertrigo, bacterial infections, varicose veins were the next common findings being more common in females compared to women.

\section{Conclusion}

Obesity is a chronic health problem, with numerous complications that affect the skin. Dermatological manifestations of obesity range from annoying to incapacitating. Early recognition and prompt attention to these dermatoses is the corner stone of appropriate management.

\section{References}

[1]. James WPT,Reeds PJ.Nutrient partitioning.In :Bray GA ,Bouchard C,James WPT,editors.Handbook on obesity.New York:Marcel Dekker,1997:555-571.

[2]. Pen a M,Bacallao J.Obesity and poverty.Washington:Scientific publication no.576.Pan American Health Organization,2000,41-49

[3]. Pi-Sunyer F.X: The obesity epidemic: pathophysiology and consequences of obesity.Obes Res10.(suppl 2):97S-104S.2002

[4]. Hud JA,Cohen JB ,Wagner JM,et al.Prevalence and significance of acanthosis nigricans in an adult obese population.Arch Dermatol.1992;128:941-944.

[5]. Garcia - Hidalgo L, Orozco TR,Gonzalez-Barranco J,et al.Dermatoses in 156 obese adults.Obesity Research. 1999;7:299-302

[6]. Katz A,Goff D,Feldman D.Acanthosis nigricans in obese patients:presentations and implications for prevention of atherosclerotic vascular disease. Dermatology online journal.2000;6(1):1-12.

[7]. JAMES P,BURKE,PHD;DANIELE.HALE,MD;HELEN P. HAZUDA ,PHD-A Quantitative scale of Acanthosis nigricans,MICHAEL P.STERN,MD DIABETES CARE,VOL 22,Number 10,October 1999. 